Research Article

\title{
Prediction of Blasting Vibration Velocity of Layered Rock Mass under Multihole Cut Blasting
}

\author{
Jie Zhu, Haixia Wei $(D$, Xiaolin Yang, and Huaibao Chu \\ School of Civil Engineering, Henan Polytechnic University, Jiaozuo, Henan, 454000, China \\ Correspondence should be addressed to Haixia Wei; whx19820828@163.com
}

Received 21 February 2021; Revised 9 April 2021; Accepted 16 April 2021; Published 23 April 2021

Academic Editor: M.I. Herreros

Copyright (c) 2021 Jie Zhu et al. This is an open access article distributed under the Creative Commons Attribution License, which permits unrestricted use, distribution, and reproduction in any medium, provided the original work is properly cited.

\begin{abstract}
In the blasting construction of underground engineering in layered rock mass, the mechanism of cut blasting and the propagation law of blasting vibration waves are very complex. In this paper, a new method for predicting the blasting vibration velocity of layered rock mass under multihole cut blasting is proposed. The key steps include determining the equivalent elastic boundary and load, establishing the multidegree freedom model of blasting vibration and its motion differential equation, and solving the motion differential equation by time-history analysis method. Two multihole cut blasting tests of different schemes were carried out in the construction site of layered rock mass, and the measured results of blasting vibration waves were obtained. By comparing the time-history curves of the predicted and measured blasting vibration velocity, it can be seen that the time-history curves predicted by the proposed method can reflect the characteristics and attenuation law of blasting vibration waves, and the predicted waveforms are similar to the measured waveforms. By using the proposed method, the prediction accuracy for the peak velocity of blasting vibration in the two tests is $93 \%$ and $94 \%$, respectively, and the prediction accuracy for the dominant frequency of blasting vibration in the two tests is $86 \%$ and $94 \%$, respectively. The prediction accuracy of the main characteristic parameters of blasting vibration waves is high. So it can be proved that the prediction method proposed in this paper is feasible in effectiveness and accuracy, which can provide important theoretical guidance for the optimization of blasting design and the control of blasting vibration in underground engineering in layered rock mass.
\end{abstract}

\section{Introduction}

The development and utilization of underground space becomes a new era hot issue for civil engineering in the twenty-first century [1]. With the rapid development of economy and urbanization, the urban development space is gradually extending from the ground and its upper space to the high-density underground space, which carries more and more urban functions (e.g., subways, underground pipe networks, underground corridors, underground storage, and underground commercial complexes) [2,3]. In the past "13th Five-Year" period (2016-2020), the underground space construction area in China increased by 844 million square meters, and its direct investment reached CNY 8 trillion. In addition to China, the development and utilization of urban underground space in other developed countries around the world has been in a rapid growth stage, such as Japan, the United States, Canada, Sweden, Finland, and France. With the large-scale development of urban underground space, more and more underground projects are constructed by drilling and blasting method. In the process of blasting construction of underground engineering, the damage of blasting vibration effect is prominent, which seriously threatens the safety of surrounding buildings and environment [4-12].

Due to the great restriction of the rock mass and high concentration of the charge, the blasting vibration intensity caused by the cut holes as the first blasting section is often the strongest $[13,14]$. Cut blasting is a key link in the control of blasting vibration effect. And the research on the cut blasting model and vibration control technology has become a hot and difficult topic in the blasting vibration field in recent years. Li et al. [15] derived an improved calculation model of the vertical cut hole considering the void effect 
based on the theory of elasticity. Wang et al. [16] established a theoretical model to reveal the cavity formation mechanism of wedge cut blasting through theoretical analysis and field test. Gao et al. [17] created numerical models of cut blasting under different initiation positions and analyzed the different cut blasting effect by numerical simulation. Ahn and Park [18] proposed an attenuation model of stress waves induced by spherical blasting source to predict the near-field range and attenuation with numerical simulation method. Eslami and Goshtasbi [19] put forward a loading model of blasting hole in the form of stress waves to simulate and analyze the explosion process by means of two types of software. Gómez et al. [20] developed a full-field solution model of the near-field blasting vibration based on the linear viscoelastic theory. Liu and Chen [21] constructed the blasting vibration waves caused by cut blasting in tunnel excavation according to the waveform function derived from the point source theory. Chen et al. [22] established a calculation model of blasting vibration caused by cut blasting under the condition of cylindrical charge with the methods of theoretical analysis and numerical simulation. Kumar et al. [23] carried out a generalized model of blasting vibration considering the effects of rock parameters based on the statistics of a large number of test data. It can be seen that people have done a lot of theoretical, numerical, and experimental research on the mechanism of cut blasting and its vibration model and achieved important results with a great reference value.

The cut blasting models or vibration models caused by cut blasting mentioned in the above literature are summarized in Table 1 . In Table $1, \sigma_{\theta B}$ is the tangential stress on the wall of empty hole $\mathrm{B} ; p_{A \max }$ is the peak pressure on the hole wall of cut hole $\mathrm{A} ; R_{A}$ is the distance from the measuring point to the centre of cut hole $\mathrm{A} ; r_{A}$ is the radius of cut hole $A ; \beta$ is the attenuation index for the stress wave; $\theta_{A}$ is the horizontal angle between the measuring point and the centre of cut hole $A ; \theta_{B}$ is the horizontal angle between the measuring point and the centre of empty hole $\mathrm{B} ; F$ is the net force from inclined cut holes perpendicular to the free surface pointing outwards; $N$ is the number of cut holes; $P_{p}$ is the perpendicular force exerted on the lateral side; $\theta$ is the angle of inclination; $Q_{w}$ is the quality factor in the frequency domain; $a_{1}$ and $a_{2}$ are the model coefficients; $R$ is the distance from the measuring point to the hole centre; $r_{0}$ is the radius of the cut hole; $V(t)$ is the final blasting vibration velocity at time $t ; \Delta t_{i}$ is the delay time between the current blasting section and the previous section; $Q_{i}$ is the charge weight of the $i$ th blasting section; $R_{i}$ is the distance from the measuring point to the hole centre of the $i$ th blasting section; $\omega_{i}$ is the angular frequency of the $i$ th blasting section; $c_{1}, c_{2}$, and $c_{3}$ are the coefficients related to the geological and topographical conditions of the site; PPV is the peak particle velocity; $Q$ is the charge weight; $d_{1}, d_{2}$, and $d_{3}$ are the parameters related to the detonation velocity of explosive; $l$ is the charge length; GSI is the geological strength index; $D$ is the scaled distance; $W$ is the unit weight.

The rock mass with layered structure in nature accounts for $2 / 3$ of the land surface. Most underground projects are related to layered rock mass. The mechanism of cut blasting and the propagation law of blasting vibration waves in layered rock mass with different physical and mechanical properties are very complex. The above research results are generally put forward on the assumption that the propagation medium is simplified as the same type of rock mass, which have great limitations when directly applied to blasting engineering in layered rock mass of different types and thicknesses. The existing models of blasting vibration caused by cut blasting have large prediction errors in practical underground engineering applications, so they cannot effectively optimize blasting parameters and control blasting vibration.

In this paper, a new method for predicting the vibration velocity caused by multihole cut blasting in layered rock mass is proposed. The key steps of the method include determining the equivalent elastic boundary and load, establishing the multidegree freedom model of blasting vibration and its motion differential equation, and solving the motion differential equation by time-history analysis method. The effectiveness and accuracy of the proposed method are proved by the field test results. This paper is organized as follows: In Section 2, the equivalent elastic boundary and load of single-hole and multihole cut blasting are determined, respectively. In Section 3, the multidegree freedom model of blasting vibration and its motion differential equation are established, and the predicted blasting vibration waves are obtained by time-history analysis method. In Section 4, the field test is carried out to verify the proposed method. In Section 5, the main conclusions are summarized and discussed.

\section{Determination of Equivalent Elastic Load of Multihole Cut Blasting}

2.1. Equivalent Elastic Load of Single-Hole Cut Blasting. When the cut blasting occurs inside the rock mass, the rock mass around the cut hole will be damaged to varying degrees. Taking the cut hole as the centre, it can be divided into the crushed zone, fracture zone, and elastic vibration zone from near to far according to the damage degrees of the rock mass. The diagram of blasting action zones is shown in Figure 1. First, the strong shock wave and the gas with high temperature and high pressure produced by the blasting operation act on the hole wall to form the crushing zone. With the attenuation of the shock wave to stress wave, radial and circumferential fractures are produced in surrounding rock mass, forming the fracture zone. When the stress wave propagates to the rock mass outside the fracture zone, it can only cause the rock particles to vibrate elastically until the energy is completely absorbed by the rock, and the corresponding zone is the elastic vibration zone.

Based on the unified constitutive relation of continuum mechanics, the boundary of the fracture zone and elastic vibration zone is regarded as the equivalent elastic boundary, and the blasting load propagating to the equivalent elastic boundary is regarded as the equivalent elastic load. For single-hole cut blasting in semi-infinite rock mass, the expression of the equivalent elastic load is as follows [24]: 
TABLE 1: Summary of cut blasting models or vibration models caused by cut blasting.

\begin{tabular}{|c|c|c|}
\hline References & Contributions & Main formulas or methods \\
\hline [15] & $\begin{array}{l}\text { Calculation model of vertical cut hole blasting considering the void } \\
\text { effect }\end{array}$ & $\sigma_{\theta B}=p_{A \max }\left(R_{A} / r_{A}\right)^{-\beta}\left[1-2 \cos 2\left(\theta_{A}+\theta_{B}\right)\right]$ \\
\hline$[16]$ & $\begin{array}{l}\text { Theoretical model of wedge cut blasting to reveal the cavity } \\
\text { formation mechanism }\end{array}$ & $F=\mathrm{NP}_{p} \cos \theta$ \\
\hline [17] & Numerical model of cut blasting under different initiation positions & Numerical simulation with LS-DYNA \\
\hline [18] & $\begin{array}{c}\text { Attenuation model of stress waves induced by spherical blasting } \\
\text { source }\end{array}$ & ical simulation with FLAC 2D \\
\hline [19] & Loading model of blasting hole in the form of stress waves & Numerical simulation with $3 \mathrm{DEC}$ and AUTO \\
\hline [20] & Full-field solution model of the near-field blasting vibration & $Q_{w}=a_{1}\left(1-e^{-a_{2}\left(R-r_{0}\right)}\right)+0.5$ \\
\hline [21] & $\begin{array}{c}\text { Superposition model of blasting vibration of cut blasting with } \\
\text { cylindrical charge }\end{array}$ & $V(t)=\sum_{i=1}^{N} c_{1}\left(\sqrt[3]{Q_{i}} / R_{i}\right)^{c_{2}} e^{-2 c_{3}\left(t-\Delta t_{i}\right)} \sin \left[\omega_{i}\left(t-\Delta t_{i}\right)\right]$ \\
\hline [22] & $\begin{array}{c}\text { Superposition model of blasting vibration with long cylindrical } \\
\text { charge }\end{array}$ & $\mathrm{PPV}=c_{1} d_{1} l e^{\left(\left(d_{2} / R\right)-d_{3}\right) l}(\sqrt[3]{\mathrm{Q}} / R)^{c_{2}}$ \\
\hline [23] & $\begin{array}{c}\text { Generalized model of blasting vibration considering the effects of } \\
\text { rock parameters }\end{array}$ & $\mathrm{PPV}=\frac{\left(0.3396 \times 1.02^{\mathrm{GSI}} \mathrm{GSI}^{1.13}\right)^{0.642} D^{-1.463}}{W}$ \\
\hline
\end{tabular}

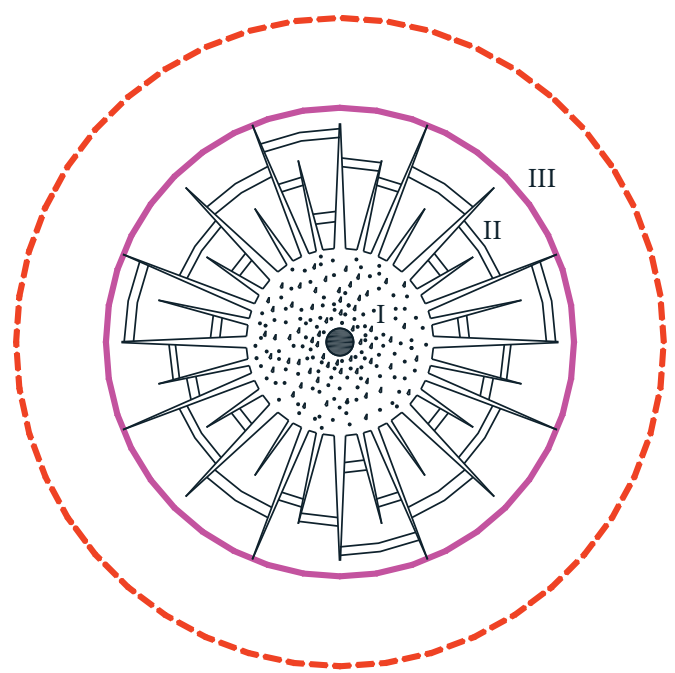

Figure 1: Diagram of blasting action zones.

$$
p_{e}(t)=p(t)\left(\frac{r_{0}}{r_{1}}\right)^{2+(\mu / 1-\mu)}\left(\frac{r_{1}}{r_{2}}\right)^{2-(\mu / 1-\mu)},
$$

where $p(t)$ is the blasting load acting on the hole wall; $r_{0}$ is the radius of the cut hole; $r_{1}$ is the radius of the crushed zone; $r_{2}$ is the radius of the fracture zone; $\mu$ is Poisson's ratio of rock mass.

The commonly used models of the blasting load acting on the hole wall include triangular load, trapezoidal load, and exponential load. Among them, the double exponential load is more commonly used because it is closer to the actual blasting load. The double exponential blasting load is usually expressed in the following form [25]:

$$
p(t)=4 p_{\max }\left(e^{-(\omega t / \sqrt{2})}-e^{-\sqrt{2} \omega t}\right)
$$

where $p_{\max }$ is the peak pressure on the hole wall, $\omega$ is the waveform parameter, $\omega=\left(\sqrt{2} C_{p} / 36\right), C_{p}$ is the $P$-wave velocity of rock mass, and $t$ is the acting time.
According to CJ theory of the detonation wave for condensed explosive, the expression of the detonation pressure is as follows [26, 27]:

$$
p_{0}=\frac{\rho_{0} D^{2}}{(1+\gamma)}
$$

where $D$ is the detonation velocity of explosive; $\rho_{0}$ is the density of explosive; $\gamma$ is the isentropic index of explosive; generally, $\gamma=3$.

For the case of coupled charge, the shock wave in rock mass is considered to be the transmission wave of the detonation wave when the explosive is in full contact with the hole wall. According to the propagation law of the shock wave in two different media, the transmission coefficient of the detonation wave can be calculated as follows [28]:

$$
T=\frac{2 \rho C_{p}}{\rho C_{p}+\rho_{0} D}
$$

where $\rho$ is the density of rock mass.

Considering the cases of both coupled charge and uncoupled charge, the expression of the peak pressure on the hole wall is as follows:

$$
p_{\max }=T p_{0}\left(\frac{a}{b}\right)^{2 \gamma}=\frac{2 \rho C_{p}}{\rho C_{p}+\rho_{0} D} \cdot \frac{\rho_{0} D^{2}}{(1+\gamma)} \cdot\left(\frac{a}{b}\right)^{2 \gamma},
$$

where $a$ is the charge diameter; $b$ is the hole diameter.

Under certain conditions, the explosive first excites the shock wave in rock mass and then attenuates into the stress wave. With the increase of distance, the peak stress will decrease rapidly. The relationship between the peak pressure and distance can be expressed as [27]

$$
\sigma_{r}=\frac{p_{\max }}{\bar{r}^{\beta}}
$$

where $\bar{r}$ is the scaled distance, $\bar{r}=\left(r / r_{0}\right)$ and $r$ is the distance from the measuring point to the charge centre; $\beta$ is the attenuation index, $\beta=2+(\mu / 1-\mu)$ for the shock wave and $\beta=2-(\mu / 1-\mu)$ for the stress wave. 


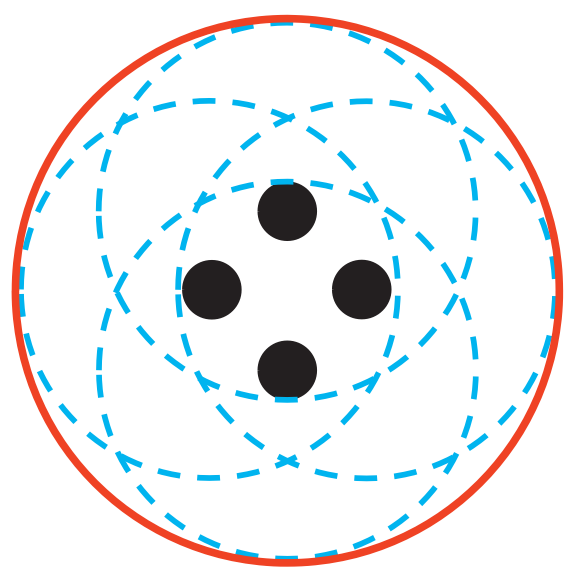

(a)

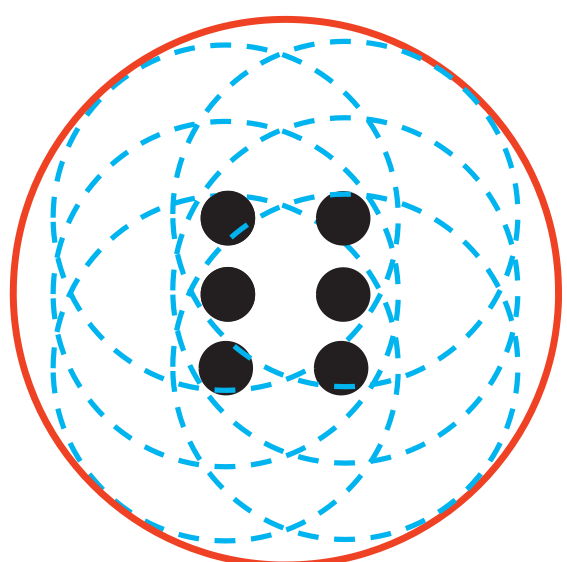

(b)

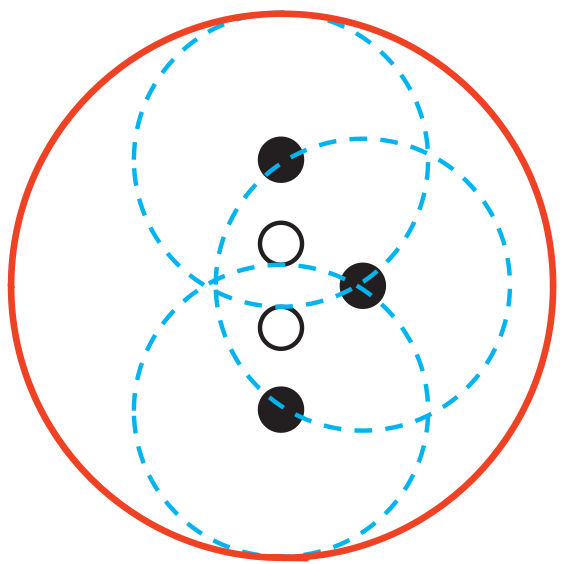

(d)

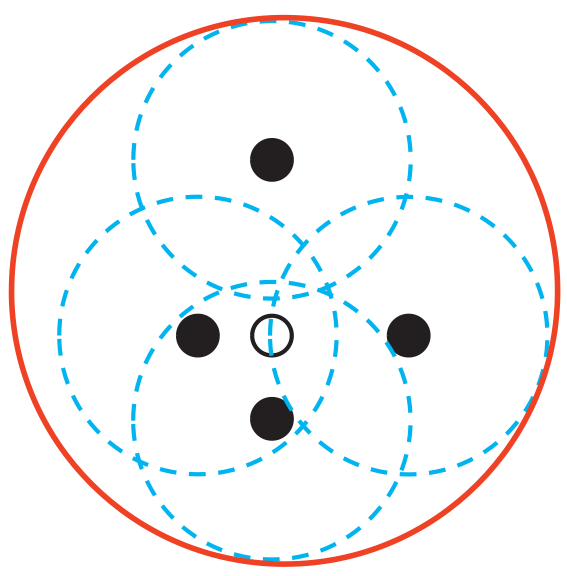

(c)

FiguRE 2: Equivalent elastic boundary diagrams of several typical cut hole arrangements. (a) Conical cut holes. (b) Wedge cut holes. (c) Spiral cut holes. (d) Bucket cut holes.

Research shows that [29] the crushed zone under blasting is the result of compression failure of rock mass, and the fracture zone is the result of tension failure of rock mass. The following expressions can be derived:

$$
\begin{aligned}
\sigma_{c d} & =\frac{p_{\max }}{\left(r_{1} / r_{0}\right)^{2+(\mu / 1-\mu)},} \\
\frac{\sigma_{t d}}{\lambda} & =\frac{\sigma_{c d}}{\left(r_{2} / r_{1}\right)^{2-(\mu / 1-\mu)}},
\end{aligned}
$$

where $\sigma_{c d}$ and $\sigma_{t d}$ are dynamic compressive strength and dynamic tensile strength of rock mass, respectively; $\lambda=(\mu / 1-\mu)$.

Then the radius of the crushed zone and fracture zone under single-hole cut blasting can be obtained:

$$
\begin{aligned}
& r_{1}=\left(\frac{p_{\max }}{\sigma_{c d}}\right)^{(1 / 2+(\mu / 1+\mu))} r_{0}, \\
& r_{2}=\left[\frac{\mu \sigma_{c d}}{(1-\mu) \sigma_{t d}}\right]^{(1 / 2-(\mu / 1-\mu))} r_{1} .
\end{aligned}
$$

By substituting equations (2), (5), (8), and (9) into equation (1), the equivalent elastic load of single-hole cut blasting can be obtained.

2.2. Equivalent Elastic Load of Multihole Cut Blasting. Without considering the interaction of each hole, the blasting of each cut hole can be regarded as the blasting of a cylindrical charge in semi-infinite medium. So the envelope of the fracture zone caused by multiple cylindrical charges can be regarded as the equivalent elastic boundary of multihole cut blasting. In this paper, the minimum envelope circle of the fracture zones caused by all the cut holes is used as the equivalent elastic boundary of multihole cut blasting. The equivalent elastic boundary diagrams of several typical cut hole arrangements are shown in Figure 2.

Multihole cut blasting includes multihole simultaneous cut blasting and multihole millisecond cut blasting. For multihole simultaneous cut blasting, considering the superposition effect of the stress waves generated by the simultaneous explosion of each cut hole on the equivalent elastic boundary, the equivalent elastic load is expressed as follows: 


$$
P_{E}(t)=\frac{N r_{2}^{2}}{r_{e}^{2}} p_{e}(t),
$$

where $N$ is the number of cut holes and $r_{e}$ is the radius of the equivalent elastic boundary.
For multihole millisecond cut blasting, considering the delay time between each blasting section, the equivalent elastic load is expressed as follows:

$$
P_{E}(t)= \begin{cases}\frac{r_{2}^{2}}{r_{e}^{2}} N_{1} p_{e}(t), & 0 \leq t<\tau_{1}, \\ \frac{r_{2}^{2}}{r_{e}^{2}}\left[N_{1} p_{e}(t)+N_{2} p_{e}\left(t-\tau_{1}\right)\right], & \\ \vdots & \tau_{1} \leq t<\tau_{2}, \\ \frac{r_{2}^{2}}{r_{e}^{2}}\left[N_{1} p_{e}(t)+N_{2} p_{e}\left(t-\tau_{1}\right)+\cdots+N_{k} p_{e}\left(t-\tau_{k-1}\right)\right], & t \geq \tau_{k-1},\end{cases}
$$

where $k$ is the number of millisecond blasting sections; $N_{k}$ is the number of cut holes in the $k$ th blasting section; $\tau_{k-1}$ is the delay time between the $(k-1)$-th blasting section and the previous section; and $\tau_{1}=0$, when $k=2$.

\section{A New Method for Predicting Blasting Vibration Velocity of Layered Rock Mass under Multihole Cut Blasting}

3.1. Multidegree Freedom Model of Blasting Vibration of Layered Rock Mass. Layered rock mass is one of the most common rock masses in underground engineering. Because of its obvious layered interface, the mechanical properties of layered rock mass under blasting load are obviously different from ordinary rock mass. In order to simplify the model, the following assumptions are made when establishing the blasting vibration model of layered rock mass:

(1) The blasting load is the only external excitation load, ignoring the change of hole-wall load on the hole axis and other loads

(2) The rock mass shows arc-shaped horizontal distribution, and the rock mass of the same layer is homogeneous and intact, only considering the influence of the interface between different layers

(3) Under the action of blasting load, the deformation of rock mass outside the equivalent elastic boundary completely satisfies Hooke's law

(4) Only the movement of layered rock mass in the vertical direction is considered

Based on the above assumptions, the layered rock mass with circular distribution of equivalent elastic load is equivalent to a multilayer elastic half-space system composed of different rock layers with different thickness, as shown in Figure 3. The rock layer where the blasting source is located is marked as $L_{0}$, and the upward rock layers are marked as $L_{1}, L_{2}, \ldots, L_{i}, \ldots, L_{n}$, respectively, whose heights are marked as $h_{1}, h_{2}, \ldots, h_{i}, \ldots, h_{n}$, respectively. For convenience of calculation, a part of the layered rock mass, symmetrically along the $45^{\circ}$ range of the central axis through the centre of the equivalent elastic boundary, is taken as the modelling object. One unit is taken as the thickness of the model object. Each rock layer is regarded as a particle, and its gravity load is concentrated on the mass centre. Assuming that these particles are supported on the ground by weightless elastic straight rods, a multidegree freedom model of blasting vibration of layered rock mass is constructed, as shown in Figure 4.

The external excitation load of the multilayer elastic halfspace system is the equivalent elastic load of multihole cut blasting propagating to the interface of rock layers $L_{0}$ and $L_{1}$, which is recorded as $F_{e}(t)$ and has the following expression:

$$
F_{e}(t)=P_{E}(t)\left(\frac{r_{e}}{r_{L 0}}\right)^{2-(\mu / 1-\mu)} \frac{\pi r_{L 0}}{2},
$$

where $r_{L 0}$ is the distance from the interface of rock layers $L_{0}$ and $L_{1}$ to the centre of the equivalent elastic boundary of multihole cut blasting.

In the multidegree freedom model of blasting vibration of layered rock mass, the weight of each layer of rock mass is

$$
m_{i}=\frac{\pi}{4}\left(r_{L i}^{2}-r_{L_{i-1}}^{2}\right) \rho_{i},
$$

where $r_{L i}$ is the distance from the interface of rock layers $L_{i}$ and $L_{i+1}$ to the centre of the equivalent elastic boundary of multihole cut blasting; and $\rho_{i}$ is the density of rock layer $L_{i}$.

3.2. Prediction of Blasting Vibration Velocity of Layered Rock Mass. According to D'Alembert's principle [30, 31], the following motion differential equation for the multidegree freedom model of layered rock mass under multihole cut blasting is established: 


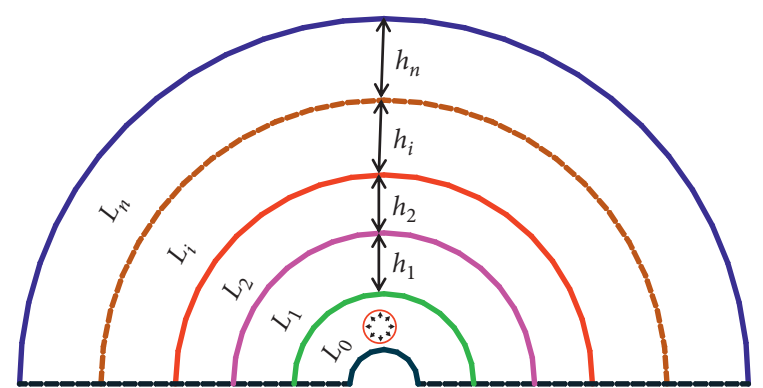

FIGURE 3: Multilayer elastic half-space system under equivalent elastic load.
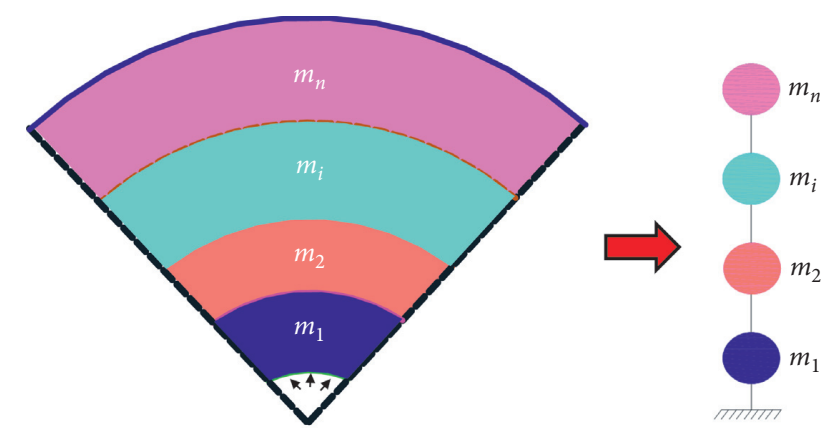

FIgURE 4: Multidegree freedom model of blasting vibration of layered rock mass.

$$
M \ddot{x}(t)+C \dot{x}(t)+K x(t)=-\left[\begin{array}{lll}
F_{e}(t) & 0 & 0
\end{array}\right]^{T},
$$

where $M$ is the weight matrix, $M=\left[\begin{array}{cccc}m_{1} & 0 & 0 & 0 \\ 0 & m_{2} & 0 & 0 \\ 0 & 0 & \ddots & 0 \\ 0 & 0 & 0 & m_{n}\end{array}\right], K$ is $K=\left[\begin{array}{ccccc}k_{1}+k_{2} & -k_{2} & 0 & 0 & 0 \\ -k_{2} & k_{2}+k_{3} & -k_{3} & 0 & 0 \\ 0 & -k_{3} & \ddots & -k_{n-1} & 0 \\ 0 & 0 & -k_{n-1} & k_{n-1}+k_{n} & -k_{n} \\ 0 & 0 & 0 & -k_{n} & k_{n}\end{array}\right]$,

$k_{i}=\left(E_{i} A_{i} / h_{i}\right), E_{i}$ is the elastic modulus of rock layers $L_{i}, h_{i}$ is the height of rock layers $L_{i}, A_{i}$ is the cross-sectional area at the mass centre of rock layers $L_{i}$, $A_{i}=(\pi / 3)\left(\left(r_{L i}^{3} /\left(r_{L i}^{2}-r_{L i-1}^{2}\right)\right)+r_{L i-1}\right), \quad C$ is the damping matrix, $\quad C=\alpha M+\beta K, \quad \alpha=4 \pi\left(\xi_{1} T_{1}-\xi_{2} T_{2}\right) /\left(T_{1}^{2}-T_{2}^{2}\right)$, $\beta=T_{1} T_{2}\left(\xi_{2} T_{1}-\xi_{1} T_{2}\right) / \pi\left(T_{1}^{2}-T_{2}^{2}\right), T_{1}$ and $T_{2}$ are the first and second natural vibration periods of the multidegree freedom model, $\xi_{1}$ and $\xi_{2}$ are the corresponding damping ratios, and generally, $\xi_{1}=\xi_{2}=0.05$.

In this paper, the concentrated impulse method, which is one of the elastic time-history analysis methods, is used to solve the motion differential equation (14). The elastic timehistory analysis method is also known as the step-by-step analysis method in mathematics. According to the input vibration load, the motion differential equation describing the elastic vibration process of the structure is directly numerically integrated by the step-by-step analysis method in the discrete-time domain. Then the vibration response of the structure at each time in the whole vibration process is calculated. The flowchart of the elastic time-history analysis method is shown in Figure 5. The basic principle of the concentrated impulse method is described as follows [32].

It is assumed that $x\left(t_{i}\right), \dot{x}\left(t_{i}\right)$, and $\ddot{x}\left(t_{i}\right)$ are, respectively, used to represent the displacement, velocity, and acceleration responses of each rock layer caused by vibration load at the moment of $t_{i}(i=0,1, \ldots, s, \ldots)$.

The initial conditions at $t_{0}$ are

$$
\begin{aligned}
x\left(t_{0}\right)= & 0, \\
\dot{x}\left(t_{0}\right)= & 0,\left(t_{0}\right)=0 . \\
& \ddot{x}
\end{aligned}
$$

The recurrence formula of the displacement is

$$
x\left(t_{s+1}\right)=2 x\left(t_{s}\right)-x\left(t_{s-1}\right)+\ddot{x}\left(t_{s}\right)(\Delta t)^{2},
$$

where $\Delta t$ is the time step.

Assuming that the acceleration changes in a straight line from $t_{0}$ to $t_{1}$, the following formula can be deduced:

$$
x\left(t_{1}\right)=\int_{0}^{\Delta t} \dot{x}(t) \mathrm{d} t=\frac{1}{6}\left[2 \ddot{x}\left(t_{0}\right)+\ddot{x}\left(t_{1}\right)\right](\Delta t)^{2}=\frac{1}{6} \ddot{x}\left(t_{1}\right)(\Delta t)^{2} .
$$

The velocity at $t_{s}$ is approximately expressed as

$$
\dot{x}\left(t_{s}\right)=\frac{x\left(t_{s}\right)-x\left(t_{s-1}\right)}{\Delta t}+\ddot{x}\left(t_{s}\right) \frac{\Delta t}{2},
$$

Then, the velocity at $t_{1}$ is

$$
\dot{x}\left(t_{1}\right)=\frac{x\left(t_{1}\right)-x\left(t_{0}\right)}{\Delta t}+\ddot{x}\left(t_{1}\right) \frac{\Delta t}{2}=\frac{x\left(t_{1}\right)}{\Delta t}+\frac{\ddot{x}\left(t_{1}\right) \Delta t}{2} .
$$

By solving formulas (14) (at $\left.t_{1}\right),(17)$, and (19), $x\left(t_{1}\right)$, $\dot{x}\left(t_{1}\right)$, and $\ddot{x}\left(t_{1}\right)$ of any layer $m_{i}$ can be obtained. Then, $x\left(t_{2}\right)$ can be obtained by formula (19). By cycling formulas (16), (14), and (18) in chronological order, all the $x\left(t_{s}\right), \dot{x}\left(t_{s}\right)$, and $\ddot{x}\left(t_{s}\right)$ of any layer $m_{i}$ from the second moment $\left(t_{2}\right)$ to the last will be solved. The velocity response of the top layer is the predicted blasting vibration velocity of layered rock mass at the ground surface corresponding to the centre of the cut holes.

\section{Verification of the Proposed Method}

4.1. An Overview of the Engineering Example. The drilling and blasting method was used in the construction section of a shallow metro tunnel in layered rock mass. To prove the effectiveness and accuracy of the proposed method for predicting blasting vibration velocity of layered rock mass under multihole cut blasting by the field test results, two field tests of cone cut blasting were carried out in the construction site. Emulsion explosive is used with the explosive density of $1200 \mathrm{~kg} / \mathrm{m}^{3}$ and the detonation velocity of $3200 \mathrm{~m} / \mathrm{s}$. The specific schemes of the two field tests are as follows.

Test 1. Three cut holes are arranged in an equilateral triangle, the hole distance is $35 \mathrm{~cm}$, the hole diameter is $40 \mathrm{~mm}$, the charge diameter is $32 \mathrm{~mm}$, the hole depth is 


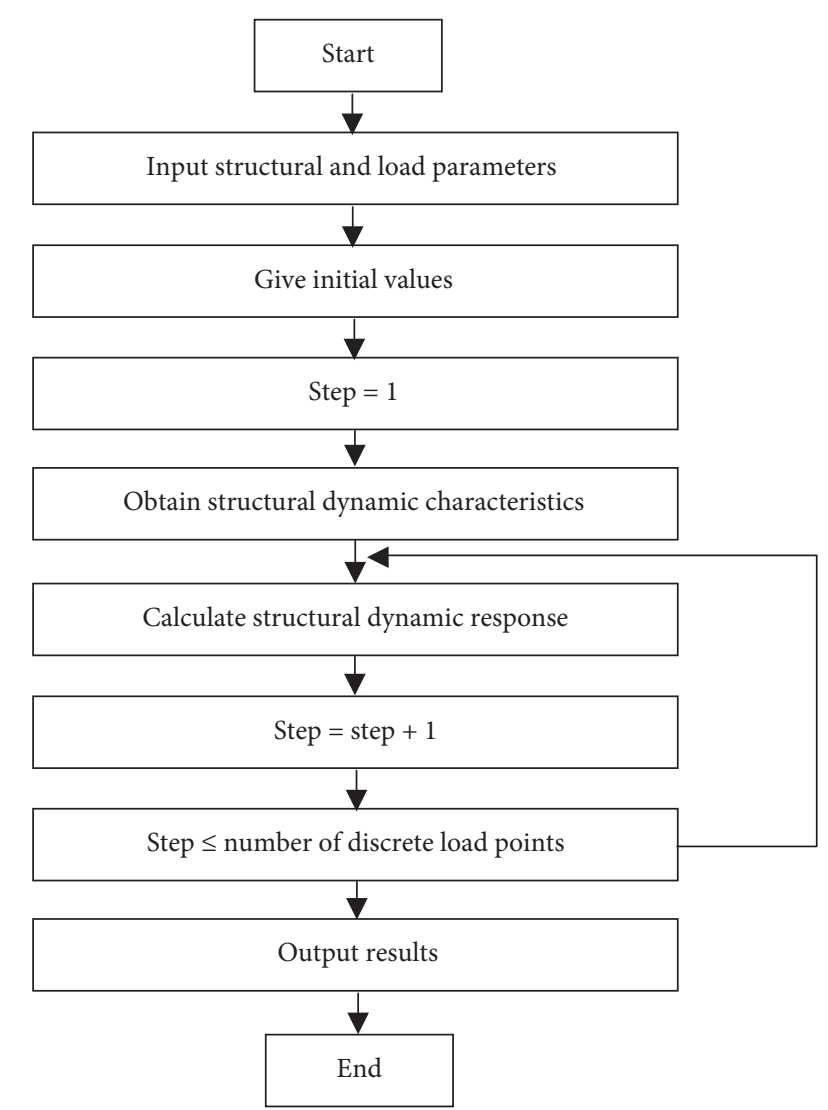

FIGURE 5: Flowchart of the elastic time-history analysis method.

$1.1 \mathrm{~m}$, the weight of single-hole charge is $0.20 \mathrm{~kg}$, and the three cut holes are detonated simultaneously.

Test 2. Four cut holes are arranged in a square, the hole distance is $40 \mathrm{~cm}$, the hole diameter is $40 \mathrm{~mm}$, the coupled charge mode is adopted, the hole depth is $1.1 \mathrm{~m}$, an empty hole with a diameter of $80 \mathrm{~mm}$ is arranged in the centre of the cut holes, the weight of single-hole charge is $0.40 \mathrm{~kg}$, two cut holes are detonated simultaneously, and the delay time is $50 \mathrm{~ms}$.

The layout of cut holes and the distribution of rock layers are shown in Figure 6. The type of the rock layer where the cut holes are located is granite. The density of granite is $2400 \mathrm{~kg} / \mathrm{m}^{3}$, the P-wave velocity is $5500 \mathrm{~m} / \mathrm{s}$, Poisson's ratio is 0.22 , the dynamic compressive strength is $2000 \mathrm{MPa}$, and the dynamic tensile strength is $180 \mathrm{MPa}$. In the two field tests, the distance from the interface of rock layers $L_{0}$ and $L_{1}$ to the centre of cut holes is $5 \mathrm{~m}$. The values of relevant parameters of each rock layer in the upper part of granite are shown in Table 2.

4.2. Result Analysis. Based on the proposed method of blasting vibration velocity of layered rock mass under multihole cut blasting, the predicted results of blasting vibration velocity at the ground surface corresponding to the centre of the cut holes in the two field tests were obtained. The comparison of time-history curves of the predicted and measured blasting vibration velocity is shown in Figure 7.
As can be seen from Figure 7, the time-history curves of blasting vibration velocity predicted by the proposed method can reflect the characteristics and attenuation law of blasting vibration waves, and the predicted waveforms are similar to the measured waveforms.

The main characteristic parameters of all blasting vibration waves are obtained. In Test 1 , the peak velocity and dominant frequency of the predicted blasting vibration wave are $1.14 \mathrm{~cm} / \mathrm{s}$ and $36.7 \mathrm{~Hz}$, respectively, and the peak velocity and dominant frequency of the measured blasting vibration wave are $1.23 \mathrm{~cm} / \mathrm{s}$ and $42.6 \mathrm{~Hz}$, respectively. In Test 2 , the peak velocity and dominant frequency of the predicted blasting vibration wave are $2.89 \mathrm{~cm} / \mathrm{s}$ and $41.5 \mathrm{~Hz}$, respectively, and the peak velocity and dominant frequency of the measured blasting vibration wave are $3.09 \mathrm{~cm} / \mathrm{s}$ and $44.2 \mathrm{~Hz}$, respectively. By using the proposed method, the prediction accuracy for the peak velocity of blasting vibration in the two tests is $93 \%$ and $94 \%$, respectively, and the prediction accuracy for the dominant frequency of blasting vibration in the two tests is $86 \%$ and $94 \%$, respectively. It can be proved that the method proposed in this paper is feasible in effectiveness and accuracy, which can provide important theoretical guidance for the optimization of blasting design and the control of blasting vibration in underground engineering in layered rock mass.

4.3. Discussion. Compared with the existing models based on simplifying layered rock mass to single rock mass, the method proposed in this paper, which is based on simplifying layered rock mass to multilayer rock mass of different types and thicknesses, is closer to the actual model. Using the proposed method, not only can the specific blasting vibration waves be predicted, but also the main characteristic parameters of blasting vibration can be accurately predicted.

However, it can be also found that the predicted values are generally lower than the measured values by comparing the time-history curves and main characteristic parameters of the predicted and measured blasting vibration velocity. Presumably, the main reasons are as follows:

(1) In establishing the equivalent elastic load of multihole cut blasting, the load in a certain range near the cut holes is applied as a uniform load on the equivalent elastic boundary, but in fact, the load in the centre of the cut holes is the most concentrated and intense

(2) The cut holes have been treated as straight cut holes, but in fact, the angle between the cut holes and the excavation face is not $90^{\circ}$

(3) The layered rock mass is considered to be in arcshaped horizontal distribution and the rock mass of the same layer is considered to be homogeneous and intact, but this is not the case

(4) Part of the parameters used in the predicted method are selected according to empirical values 


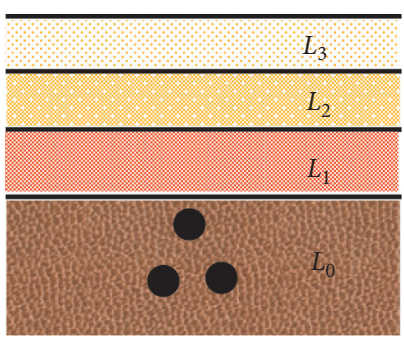

(a)

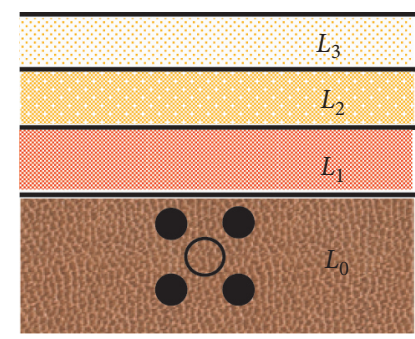

(b)

FIgURE 6: Layout of cut holes and distribution of rock layers. (a) Test 1. (b) Test 2.

TABLE 2: Parameters of each rock layer in the upper part of granite.

\begin{tabular}{lcccc}
\hline No. & Rock type & Layer depth $(\mathrm{m})$ & Elastic modulus $(\mathrm{GPa})$ & $\mathrm{Density}\left(\mathrm{kg} / \mathrm{m}^{3}\right)$ \\
\hline$L_{1}$ & Moderately weathered granite & 10 & 30 & 2300 \\
$L_{2}$ & Sandstone & 5 & 10 & 2100 \\
$L_{3}$ & Clay & 3 & 4 & 1600 \\
\hline
\end{tabular}

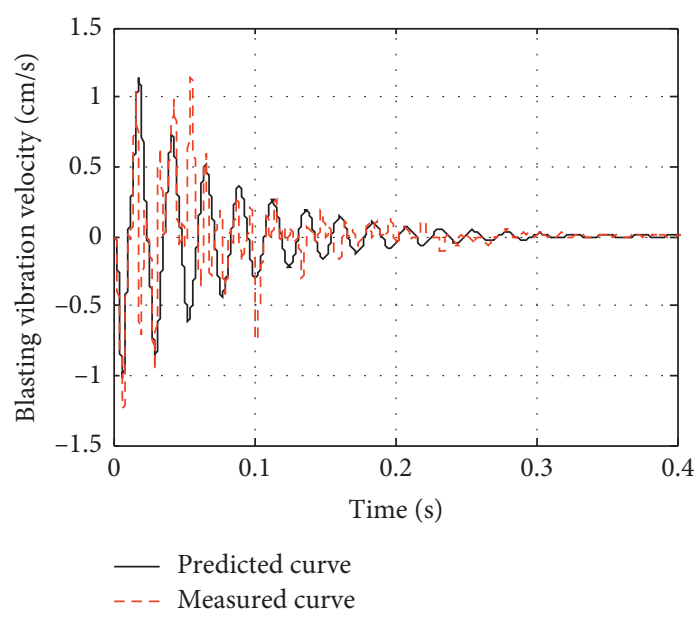

(a)

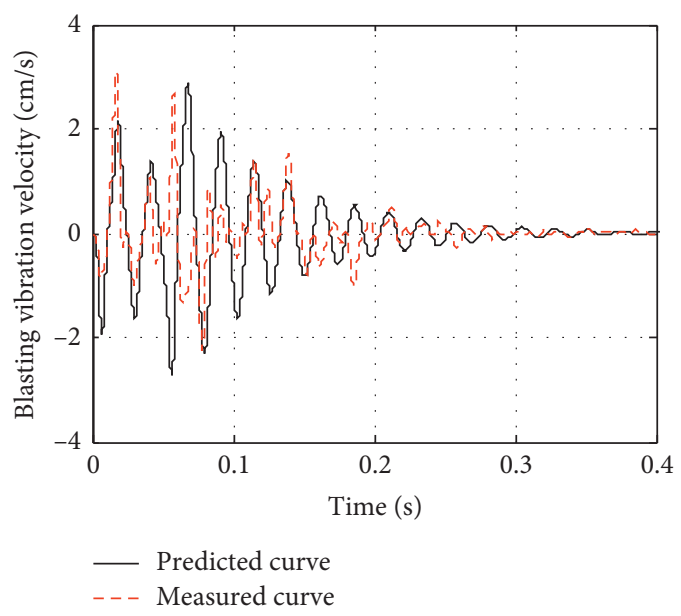

(b)

Figure 7: Comparison of time-history curves of predicted and measured blasting vibration velocity. (a) Test 1. (b) Test 2.

\section{Conclusions}

(1) A new method for predicting the blasting vibration velocity of layered rock mass under multihole cut blasting is proposed in this paper. The detailed steps of the method include the following: calculate the peak pressure on the hole wall of a single cut hole; construct the blasting load acting on the hole wall of a single cut hole; calculate the radius of the crushed zone and fracture zone under singlehole cut blasting; calculate the equivalent elastic load of single-hole cut blasting; determine the equivalent elastic boundary and load of multihole cut blasting; establish the multidegree freedom model of blasting vibration of layered rock mass; establish the motion differential equation of the multidegree freedom model of blasting vibration; solve the motion differential equation by timehistory analysis method.
(2) Two field tests of multihole cut blasting were carried out with different schemes. The field test results show that the time-history curves of blasting vibration velocity predicted by the proposed method can reflect the characteristics and attenuation law of blasting vibration waves, and the predicted waveforms are similar to the measured waveforms. In addition, the prediction accuracy of the main characteristic parameters of blasting vibration waves is high. So the prediction method proposed in this paper is feasible in effectiveness and accuracy, which can provide important theoretical guidance for the optimization of blasting design and the control of blasting vibration in underground engineering in layered rock mass.

(3) The purpose of this paper is to try to put forward a prediction method suitable for blasting excavation engineering in layered rock mass. It should be noted 
that the feasibility of the proposed method needs more tests to verify. In this paper, the equivalent elastic load, the angle between the cut holes and the excavation face, the mechanical parameters of layered rock mass, and other problems are simplified. The actual engineering conditions in layered rock mass will be more complex, and more reasonable prediction methods considering more practical factors need to be further developed on this basis.

\section{Data Availability}

The data used to support the findings of this study are included within the article.

\section{Conflicts of Interest}

The authors declare that there are no conflicts of interest regarding the publication of this paper.

\section{Acknowledgments}

This work was supported by the National Natural Science Foundation of China (nos. 51874123 and 51504082).

\section{References}

[1] K. S. Sakyi, K. Benjamin, and K. Godson, "Seismic response analysis of underground structures," Journal of Environment and Earth Science, vol. 8, no. 5, pp. 48-71, 2018.

[2] N. Bobylev, "Underground space as an urban indicator: measuring use of subsurface," Tunnelling and Underground Space Technology, vol. 55, pp. 40-51, 2016.

[3] H. Admiraal and A. Cornaro, Underground Spaces Unveiled: Planning and Creating the Cities of the Future, ICE Publishing, London, England, UK, 2018.

[4] M. Khandelwal and M. Saadat, "A dimensional analysis approach to study blast-induced ground vibration," Rock Mechanics and Rock Engineering, vol. 48, no. 4, pp. 727-735, 2015.

[5] J. Zhou, X. Shi, and X. Li, "Utilizing gradient boosted machine for the prediction of damage to residential structures owing to blasting vibrations of open pit mining," Journal of Vibration and Control, vol. 22, no. 19, pp. 3986-3997, 2016.

[6] H. Eskandar, E. Heydari, M. Hasanipanah, M. Jalil Masir, and A. Mahmodi Derakhsh, "Feasibility of particle swarm optimization and multiple regression for the prediction of an environmental issue of mine blasting," Engineering Computations, vol. 35, no. 1, pp. 363-376, 2018.

[7] M. Wang, X. Shi, and J. Zhou, "Charge design scheme optimization for ring blasting based on the developed Scaled Heelan model," International Journal of Rock Mechanics and Mining Sciences, vol. 110, pp. 199-209, 2018.

[8] H. Aawal and A. K. Mishra, "Modified scaled distance regression analysis approach for prediction of blast-induced ground vibration in multi-hole blasting," Journal of Rock Mechanics and Geotechnical Engineering, vol. 11, no. 1, pp. 202-207, 2019.

[9] J. Zhou, P. G. Asteris, D. J. Armaghani et al., "Prediction of ground vibration induced by blasting operations through the use of the Bayesian Network and random forest models," Soil Dynamics and Earthquake Engineering, vol. 139, p. 12, Article ID 106390, 2020.
[10] H. Wei, J. Chen, J. Zhu, X. Yang, and H. Chu, "A novel algorithm of nested-ELM for predicting blasting vibration," Engineering with Computers, vol. 2, 2020.

[11] A. Mahdiyar, D. J. Armaghani, M. Koopialipoor et al., "Practical risk assessment of ground vibrations resulting from blasting, using gene expression programming and monte carlo simulation techniques," Applied Sciences, vol. 10, no. 2, p. $17,2020$.

[12] A. I. Lawal, S. Kwon, and G. Y. Kim, "Prediction of the blastinduced ground vibration in tunnel blasting using ANN, moth-flame optimized ANN, and gene expression programming," Acta Geophysica, vol. 69, no. 1, pp. 161-174, 2021.

[13] H. Shi and J. Zhang, "Blasting vibration effect of wedge cut blasting in parallel small-distance tunnel," Chinese Journal of Underground Space and Engineering, vol. 15, no. 2, pp. 607621, 2019.

[14] Q. Li, X. Wei, J. Zheng et al., "Study and application of profile control for full section excavation of large section tunnel in grade IV surrounding rock," Journal of Highway and Transportation Research and Development, vol. 37, no. 3, pp. 88-94, 2020.

[15] Q. Li, Z. Wu, and W. Huang, "Improvement and analysis of calculation model for empty hole effect in parallel cut," Journal of Mining \& Safety Engineering, vol. 35, no. 5, pp. 925-930, 2018.

[16] Z. Wang, X. Gu, W. Zhang et al., "Analysis of the cavity formation mechanism of wedge cut blasting in hard rock," Shock and Vibration, vol. 2019, Article ID 1828313, 10 pages, 2019.

[17] Q. Gao, W. Lu, Z. Leng et al., "Optimization of cut-hole's detonating position in tunnel excavation," Journal of Vibration and Shock, vol. 37, no. 9, pp. 8-16, 2018.

[18] J.-K. Ahn and D. Park, "Prediction of near-field wave attenuation due to a spherical blast source," Rock Mechanics and Rock Engineering, vol. 50, no. 11, pp. 3085-3099, 2017.

[19] M. Eslami and K. Goshtasbi, "Blasting damage predictions by numerical modeling in Siahbishe pumped storage powerhouse," Journal of The Institution of Engineers (India): Series D, vol. 99, no. 1, pp. 133-146, 2018.

[20] S. Gómez, J. A. Sanchidrián, and P. Segarra, "Near-field vibration from blasting and rock damage prediction with a full-field solution," Journal of Rock Mechanics and Mining Sciences, vol. 134, p. 18, Article ID 104357, 2020.

[21] X. Liu and S. Chen, "Prediction of surface vibration waveform caused by cuthole blasting in tunneling," Chinese Journal of Geotechnical Engineering, vol. 41, no. 9, pp. 1731-1737, 2019.

[22] S. Chen, J. Wu, and Z. Zhang, "Blasting vibration characteristics and PPV calculation formula considering cylindrical charge length," Environmental Earth Sciences, vol. 76, no. 20, p. 12, 2017.

[23] R. Kumar, D. Choudhury, and K. Bhargava, "Determination of blast-induced ground vibration equations for rocks using mechanical and geological properties," Journal of Rock Mechanics and Geotechnical Engineering, vol. 8, no. 3, pp. 341349, 2016.

[24] J. Yang, W. Lu, M. Chen et al., "An equivalent simulation method for blasting vibration of surrounding rock," Explosion and Shock Waves, vol. 32, no. 2, pp. 157-163, 2012.

[25] X. Wang, Y. Huang, L. Peng et al., "Study on full-time load function of tunnel blasting and its application," Journal of Railway Science and Engineering, vol. 16, no. 1, pp. 144-151, 2019.

[26] W. Fickett and W. C. DavisUniversity of California Press, Detonation Berkeley, CA, USA, 1979. 
[27] J. Henrych, The Dynamics of Explosion and its Use, Elsevier Scientific Publishing Company, New York, NY, USA, 1979.

[28] W. Wang, X. Li, L. Shi et al., "Discussion on decoupled charge loosening blasting in deep rock mass," Rock and Soil Mechanics, vol. 29, no. 10, pp. 2837-2842, 2008.

[29] F. Wu, H. Liu, Y. Ren et al., "Formation mechanism and main controlling factors of rock's initial damaged zone under explosive impact effect," Explosion and Shock Waves, vol. 36, no. 5, pp. 663-669, 2016.

[30] M. Malckincjad and R. Rahgoza, "An analytical model for dynamic response analysis of tubular tall buildings," The Structural Design of Tall and Special Buildings, vol. 23, no. 1, pp. 67-80, 2014.

[31] A. M. Kabe and B. H. Sako, Structural Dynamics Fundamentals and Advanced Applications, Academic Press, Cambridge, MA, USA, 2020.

[32] G. He, Q. Yan, and J. Yuan, Elastoplastic Seismic Response of Engineering Structures, China Railway Publishing House, Beijing, China, 2005. 